\title{
STUDENTS`ACHIEVEMENT IN ONLINE TEST AND MEASUREMENT COURSE IN SYNCHRONOUS AND ASYNCHRONOUS E-LEARNING PLATFORM
}

\author{
Basil C. E. Oguguoi, \\ Christopher A. Ocheni, \\ Femi K. Adebayo \\ University of Nigeria, \\ Nsukka, Nigeria
}

\begin{abstract}
:
Studies reviewed on student's achievement in synchronous and asynchronous learning shows mixed results. This study determines whether there exists a significant difference in the achievement of students in online test and measurement course in synchronous and asynchronous e-learning platform. The participants consist of 348 under graduate students of National Open University of Nigeria in online test and measurement course. The researchers employed ex-post facto research design for the study and the instrument used for data collection was the Students Test and Measurement Course Proforma (STMCP). The result revealed that synchronous e-learning improved students' academic achievement more than asynchronous e-learning. It was also found that gender of students significantly influenced their academic achievement in both synchronous and asynchronous learning in favour of the male students. The findings of this study will assist education planners and policy makers in planning decision making process which must come from the students as well as the society in general. Thus, education planners need to review the policies and distance learning curriculum in order to emphasize the importance of distance learning as well as facilitate decisions that will make available relevant and quality distance learning materials which will invariably improve students.
\end{abstract}

Keywords: e-learning platform, synchronous and asynchronous, test and measurement, distance learning, undergraduate education

\section{Introduction}

The advent of technology has redefined methodologies and brought about paradigm shifts in the approaches of doing things as it has facilitated improvement and advancement in different areas of human endeavours and across different sectors such

i Correspondence: email basil.oguguo@unn.edu.ng 
as the economic sector, the health sector, production sector and a list of others. The education sector of course is not an exception to this advancement as different methods of teaching and learning have emerged. One of such advancement in the education sector is the emergence of distance learning. The introduction of distance learning as made possible by advancement in technology has taken education beyond the confines of the traditional or classroom settings of teaching and learning.

Distance learning has been defined by several authors. As reported by Miles (2014), the United States Distance Learning Association (USDLA) referred to distance education as a generic or an all-inclusive term that is used to refer to the physical separation of teachers and learners. It is referred to as a distance learning or distributed learning that requires the application of information technology to educational and student-related activities linking teachers and students in differing places. This definition implies that in distance learning, the learners and the instructors are separated by distance and all forms of communication and activities are mediated by electronic means. This means that such technological means as audio, video, computers and prints are employed to bridge the instructional gap. Frank (2008) defined distance education as any field of education that focuses on the pedagogy, technology, and instructional system design that is effectively incorporated in delivering education to students who are not on site to receive the education physically. Distance learning is any kind of learning that is facilitated with the use of technology and takes place beyond physical space and time. This enables students to interact synchronously or asynchronously while making use of online educational tools. This gives endless training opportunities with distance learning courses (Papadopoulou, 2020). Distance learning entails online education of students where learning materials are sent over the internet such that students can work from home and not classroom (Techsmith, 2021). These definitions mean that any form of learning activity where teaching and learning are done over the internet such that the learners and instructors are separated by distance and time is referred to as distance learning. In essence, this kind of learning does not necessary require the learners and instructor to be at the same place in the same time. Thus, students can learn at their own pace and time.

The importance of distance education cannot be overemphasized. Many researchers have outlined the benefits of distance education to the education system. According to Tichauer (2015), some of the benefits of distance learning include cost effectiveness, ease of learning, ability to combine work and study, and the freedom to study at one's own pace and time. Digital Technology (DT, 2020) further added that other benefits of distance learning are location independent, low cost of study, flexible learning, quick access to digital and learning materials or contents, broader networking opportunities and a whole lot of other benefits. To this effect, distance education may be regarded as a powerful asset to the education system all over the world. It is possible to say here that these benefits of distance education are essential to the development of any nation especially in the area of education. More so, Simon (2020) added that selfinspiration, adaptability and freedom, easy access, virtual trip etc. are other importance 
of distance education. Distance education has become prevalent in this age of technology. According to Hanover Research (HR, 2011), distance learning is prevalent because several studies have validated its practice and have revealed that no significant difference exist between students of traditional and distance education. In this regard, it means that distance learning is as effective as the traditional learning approach. Moreover, it is in the realization of the importance of distance learning that it has continually gained dominance across every nations of the world. This is evident in the Nigerian National Policy on Education (NPE) handbook.

\section{Literature Review}

The Nigerian National Policy on Education, in a bid to stress on the importance of distance education has stated that distance education in Nigeria shall be promoted nationwide in collaboration with the Federal, State and Local Government Education authorities (FRN, 2014 p.35). Conceivably, this is to facilitate the integration of distance learning into the education system which will thus enhance rapid development in the education system.

Basically, distance education has been classified into six (6). These are video conferencing, open schedule online courses, hybrid distance education, computer-based distance education, fixed time online course, and synchronous and asynchronous distance education. Videoconferencing is concerned with a situation where two or more participants (learners and instructor) use video to connect over the internet making use of tools such as Zoom, Adobe Connect, Google meet etc. to facilitate learning regardless of the distance of separation. Open schedule online courses on the other hand falls under the category of asynchronous learning, here students are given freedom and provided with online based textbooks, emails, bulletin board etc. to complete their course work with a set deadline. Hybrid distance education deals with the combination of synchronous and asynchronous learning in which learners receive deadline for task completion and submission using forum(s). Computer-based distance education refers to a learning setting where students are expected to meet in a classroom or computer laboratory at a specified time in order for learning to take place. Fixed time course distance education which is one of the most common types of distance education entails a learning situation where learning courses are made available online but students need to log-in to their learning portal at a designated time for learning to take place. Synchronous and asynchronous distance learning refers to a learning situation where learners are expected to be online at the same time for learning to take place (synchronous learning) and similarly, at different time for learning to take place (asynchronous learning).

\subsection{Synchronous Learning}

The advent of synchronous and asynchronous distance learning has been very profitable to the education sector all over the world. Synchronous learning according to Simonson, 
et al (2012) involves any learning situation that requires the use of digital tools and contents ranging from telephone calls and video conferencing to voice over the internet protocol (VoIP) and video broadcast over the internet to facilitate learning. Equally, Great Schools Partnership (GSP) (2020) defined synchronous distance education as a term mostly used to refer to various forms of televisual, digital, and online learning in which students learn from instructors, colleagues, or peers in real time, but not in person usually through media as educational video conferences, interactive webinars, chat-based online discussions etc. These definitions imply that learning activities that requires the presence of learners and instructors who are separated by physical distance in real time with the use of information technology means and learning platforms such as Google meet, zoom, Microsoft teams, skype, Moodle etc. can be termed synchronous distance learning. Okoulina (2020) referred to synchronous learning as any form of training activity where learners participate simultaneously either online or offline. In the words of Higley (2013), synchronous learning enhances efficient education and provides both the students and teachers the various ways and opportunities to network and share idea and collaborating in real-time. Hrastinki (2008) further added that synchronous learning improves learners and instructor's relationship which can thus lead to increased students' participation in online study. More so, it has been added that synchronous education facilitates prompt feedback, social interaction, collaboration, student's engagement etc. (Benett, 2020).

\subsection{Asynchronous Learning}

Asynchronous learning on the other hand is a student-centered teaching and learning method that offers learners the opportunity to learn at different times and different location as particular to each learner (Finol, 2020). The term applies to various forms of digital and online learning in which students learn on their own, at their home, with instruction that is delivered via the internet in real time (Griffith et al., 2021). In asynchronous learning, instructors usually set up learning path which the students can engage with at their own time and pace. According to Littlefield (2018), it entails any kind of distance education that occurs when learners and instructor separated by distance interact together in different time. It often requires the use of such technologies as e-mail, e-courses, online forums, audio recordings and video recordings (Littlefield, 2018). Viewsonic (2020) also defined asynchronous learning as a type of distance learning in which the learners and the teacher are not communicating directly in real-time. Furthermore, Hammond et al as cited in Dada, et al. (2019) defined asynchronous education as a type of e-learning which makes learning available and accessible whenever it is required thereby giving learners the flexibility to learn. This is a learning situation that does not require the presence of both students and teachers online simultaneously; thus, teachers can drop learning materials and resources for students through platforms while students go online at their own pace and time to interact with the materials without the supervision of the teacher or instructor. Asynchronous learning has been found to be very beneficial to students. According to Benett (2020), asynchronous learning creates room for convenience and reinforcement in learning, 
flexibility and learners ' control while learning. Consequently, Littlefield (2018) added that asynchronous learning is affordable, flexible, practicable, increases students' motivation and can be undertaken by students at their own space and time regardless of location. In addition to the above benefits of asynchronous learning, the findings of Hammond et al as pointed out by Dada et al. (2019) revealed that other benefits of asynchronous learning are its flexibility in learning process and content, its cheap nature and the ease with which it can be set up. From the forgoing, it is imperative that the introduction of distance education to the teaching and learning process is a great improvement to the education sector of every nation across the world including Nigeria. More so, considering the importance of synchronous and asynchronous distance education, one could most likely say that online courses such as test and measurement courses are now better presented or taught to students across higher institutions especially in National Open Universities in Nigeria by adapting synchronous and asynchronous learning approach.

\subsection{Test and Measurement Course}

Test and measurement course also called measurement and evaluation course is concerned with the knowledge of introductory statistics and educational measurements as well as educational research. It targets to improve measurements of human behaviour, learning and the development in the fields of education, social and behavioural science (The University of Adelaide, 2014). This test and measurement course is designed to assist students understand measurement and the development of testing as well as its importance in education. Test and measurement course exposes students to various concepts of educational objectives as well as the taxonomy of educational measures and the descriptions of the learning domains. It discusses classroom test as well as general instruments for testing. Test and measurement course also exposes students to basic statistical measures as well as their application in the field of education and research. The knowledge acquired from this course can assist students in their final year research work as well as other relevant course works. Considering the importance of online test and measurement course, it is necessary the students of National Open University of Nigeria who offers this course either synchronously or asynchronously achieve highly.

\subsection{Academic Achievement}

Academic achievement in online courses under these forms of distance education are likely to improve. Perhaps, this is evident in the finding of (Ducan, et al., 2012) who identified that synchronous and asynchronous distance learning facilitate students' learning and influences their academic achievement. This is also in line with the view of Dada et al. (2019) that synchronous and asynchronous distance learning approaches contribute in high proportion to students' academic achievement. Academic achievement refers to students ' performance or outcomes in intellectual domains taught at the school, college or university. It is an indicator for measuring the level of progress and prosperity of an individual in the society (Spinath, 2012). More so, (Strenze, 2007; Jonsdottir, 2012) 
stated that academic achievement represents performance of results that shows the level to which an individual has specific objectives or goals that appeared to be the focus of activity (ies). According to the authors, academic achievement prepares learners for future career and also helps them find themselves in competitive fields. It can however limit students' opportunities in the aspect of further education or career. To this regard, it is almost clear to say that academic achievement plays important roles in the field of education both to students and to other educational stakeholders.

Considering the place of academic achievement, one would expect that any teaching and learning situation such as synchronous and asynchronous online learning adopted in teaching students should facilitate students' improvement with respect to their academic achievements. However, studies have shown that researchers are having a contrary view on the influence of both synchronous and asynchronous distance education approach as some researchers believe that synchronous distance learning enhances students' academic achievement more than asynchronous learning; whereas, other researchers are having a contrary view. According to Ogbonna, et al. (2019) in their study on synchronous verses asynchronous e-learning in teaching word processing using an experimental approach, it was found that students exposed to asynchronous distance learning achieved more academically than those exposed to synchronous learning. This finding also agrees with the finding of Berry (2017) who revealed that students exposed to asynchronous learning achieved significantly higher than those exposed to synchronous learning in a study on the educational outcomes of synchronous and asynchronous high school students using a quantitative causal-comparative study of online Algebra 1. Contrary to the above views, Ducan, et al (2012) in their study on the effect of synchronous and asynchronous participation on students ' performance in online accounting courses stated that synchronous distance learning improved students' academic achievement twice as more than asynchronous distance learning. However, Dada et al. (2019) found that both synchronous and asynchronous distance learning facilitates students ' academic achievement positively. LeShea (2013) investigated on the effect of synchronous class sessions on students' academic achievement and levels of satisfaction in an online instruction to computers course found out that synchronous learning does not improve students`academic achievement. Malik, et al (2017) found a significance difference in students' responses with respect to the effectiveness of synchronous and asynchronous learning. The authors revealed that Male students indicated higher preference for synchronous and asynchronous learning over female students. However, students showed more interest in synchronous learning as they had more marks in synchronous activities.

The level of disagreement among researchers on the most effective and efficient form of distance learning with respect to students` academic achievement has raised a lot of concern among stakeholders as most stakeholders especially students are confused on the best form of distance learning that will help in contributing and improving their academic achievement. This is evident in the fact that why some researchers believe that asynchronous distance education is more effective in improving students' academic 
achievement, others are in support of synchronous distance learning; whereas, others believe that no significant difference exist between both methods with respect to students' academic achievement. This kind of disagreement needs to be investigated. Thus, it is important that this present study be carried out to assess students' academic achievement in synchronous and asynchronous distance learning using an online test and measurement course.

The importance of distance learning in the field of education has been overwhelming. This importance has caused this kind of education (Distance Learning) to witnessed enormous advancement and growth in recent times. As a result, many nations and particularly, Nigeria at the national level has already included distance learning in the national curriculum. Several higher institutions of learning in the country especially the National Open Universities have equally taken the bold step of integrating distance learning. Literature have shown that several forms of distance learning such as the synchronous and asynchronous distance learning have been effective as the traditional classroom teaching and learning in contributing to students' academic achievement. However, researchers seem to believe that one of these forms of distance learning is more effective in improving students 'academic achievement than the other. In the light of this, researchers have attempted to find out which of this type of distance learning is more effective in improving students 'academic achievement. Regardless of all these efforts, extensive literature reviewed shows that researchers are still in disagreement on the best form of distance learning between these two methods. This implies that this disagreement among researchers will linger on if it is not addressed. The problem of this study in an interrogative statement is, what is the difference in the academic achievement of distance learning students in online test and measurement course in synchronous and asynchronous learning in National Open University of Nigeria? Generally, the purpose of this study is to determine whether there exists a significant difference in the achievement of students in online test and measurement course in synchronous and asynchronous learning in the National Open University of Nigeria.

\section{Material and Methods}

\subsection{Design of the Study}

This study adopted the ex-post facto research design. This research design according to Nworgu (2015) involves establishing a cause and effecting a relationship between variables that cannot be manipulated. This design is appropriate for this study because the researchers does not have the ability to influence the scores (data) of students in online test and measurement course in synchronous and asynchronous learning that will be used for the study.

\subsection{Participants}

The participants consist of $(n=348) 400$ level undergraduate students of test and measurement course consisting of 196 synchronous learning (109 males and 87 females) 
and 152 asynchronous learning students (79 males and 73 females) in the 2018/2019 academic session in the National Open University of Nigeria, Enugu study center and they were purposively selected.

\subsection{Research Instrument}

The instrument that was used in the collection of data for this study was "Students Test and Measurement Course Proforma (STMCP)". The instrument STMCP comprised students score records of the 400level test and measurement undergraduate students for 2018/2019 academic session. The scores obtained was transformed into standard scores and used for the analysis.

\subsection{Validity and Reliability}

The instrument STMCP underwent face validation. STMCP was given to three experts for face validation. The face validation was to make sure that the results are correct and accurate. To estimate the reliability index for the instrument STMCP, the scores of students on the proforma were subjected to reliability analysis using Kudder-Richardson formula $21\left(\mathrm{~K}-\mathrm{R}_{21}\right)$ to determine the estimate of internal consistency of the instrument. The reliability index was arrived at to be 0.82 .

\subsection{Data Analysis}

The data for this study was analysed using SPSS version 23.00. The data collected was subjected to score transformation statistics (z-score and T-Score). The essence of this transformation is to ensure comparability of the scores. Mean and standard deviation was then used to answer the research questions while the hypotheses were tested at 0.05 level of significance using t-test.

\section{Results and Discussion}

\subsection{Results}

Table 1: $t$-test comparison of the mean scores of student's academic achievement in online test and measurement course in synchronous and asynchronous learning

\begin{tabular}{|l|c|c|c|c|c|c|c|}
\hline Distance Learning Types & $\mathbf{N}$ & $(\overline{\boldsymbol{X}})$ & SD & Df & t-cal & Sig.(2-tailed) & Decision \\
\cline { 1 - 7 } Asynchronous & 152 & 49.7597 & .92518 & \multirow{2}{*}{346} & -4.034 & \multirow{2}{*}{0.000} & Sig. \\
\hline Synchronous & 196 & 50.1864 & 1.01821 & & & \\
\hline
\end{tabular}

Table 1 shows the mean and standard deviation of the difference in the mean academic achievement scores of students in online test and measurement course in synchronous and asynchronous distance learning. The result indicates that the mean achievement scores of the students are relatively high. However, the mean achievement scores of students in synchronous learning which is 50.1864 is slightly higher than that of students in asynchronous learning which is 49.7597 . The standard deviation of the scores on students in both synchronous and asynchronous learning is also relatively high which 
indicate a wide spread in the scores of students. The t-test critical value of -4.034 has an associated probability value of 0.000 which is less than the a-priori probability value of 0.05 level of significance. This indicates that there is a significant difference in the mean achievement scores of students under synchronous and asynchronous learning in online test and measurement course. Thus, the null hypothesis is rejected. This implies that the observed difference in the mean achievement of students under synchronous and asynchronous learning is significant; therefore, students in synchronous learning achieved higher than those in asynchronous learning in online test and measurement course.

Table 2: $t$-test comparison of the mean scores of male and female student's academic achievement in online test and measurement course in synchronous learning

\begin{tabular}{|l|c|c|c|c|c|c|c|}
\hline Gender & $\mathbf{N}$ & $(\overline{\boldsymbol{X}})$ & SD & Df & t-cal & Sig. (2-tailed & Decision \\
\cline { 1 - 6 } Male & 109 & 50.6315 & .76248 & \multirow{2}{*}{194} & 7.842 & 0.000 & Sig. \\
\cline { 1 - 5 } Female & 87 & 49.6286 & 1.02705 & & & & \\
\hline
\end{tabular}

Table 2 shows the mean achievement scores of male and students in online test and measurement course under synchronous learning. The result shows that the male students have a mean score of 50.6315 while the female students have a mean score of 49.6286. This indicate that the mean score of the male students is slightly higher than that of the female students. The standard deviation of the scores of males $(0.7624$ and females (1.02705) students in synchronous learning is relatively high, implying that there is a difference in among scores. From the table the t-value of 7.842 has an associated probability value of 0.000 which is less than 0.05 level of significance. Therefore, the null hypothesis is rejected. This means that a significant difference exists in the mean academic achievement of male and female students in online test and measurement course under synchronous learning. Thus, the male students achieved significantly higher than the female students in online test and measurement course under synchronous learning.

Table 3: t-test comparison of the mean scores of male and female student's academic achievement in online test and measurement course in asynchronous learning

\begin{tabular}{|l|c|c|c|c|c|c|c|}
\hline Gender & $\mathbf{N}$ & $(\overline{\boldsymbol{X}})$ & SD & Df & t-cal & Sig. (2-tailed) & Decision \\
\cline { 1 - 7 } Male & 79 & 50.0977 & .78956 & \multirow{2}{*}{150} & \multirow{2}{*}{5.053} & \multirow{2}{*}{0.000} & Sig. \\
\hline Female & 73 & 49.3939 & 0.92666 & & & & \\
\hline
\end{tabular}

As shown in the above table, the mean score of the male students is slightly higher than that of the female students. More so, the standard deviation of the scores of male and female students in asynchronous learning is 0.78956 and 0.92518 respectively which appears to be relatively high implying that there is a high variation among scores of students. The result shows that the $\mathrm{t}$-value of 5.053 has an associated probability value of 0.000 which is less than the alpha value of 0.05 level of significance. Hence, the null hypothesis is rejected. This means that there is a significant difference in the mean 
academic achievement of male and female students in online test and measurement course under asynchronous learning. Thus, the male students achieved significantly higher than the female students in online test and measurement course under synchronous learning.

\subsection{Discussion}

This study reports the academic achievement of undergraduate students in online test and measurement course in synchronous and asynchronous e-learning platform. The result of the study showed that the mean achievement scores of students in online test and measurement course under synchronous and asynchronous learning are relatively high. However, students under synchronous learning have a higher mean value than those under asynchronous learning. The result revealed a significant difference in the mean achievement of students in both distance learning approach in favour of the students in synchronous learning. Thus, students under synchronous learning achieved significantly higher than their counterpart under asynchronous learning in online test and measurement course. This finding is in agreement with the findings of Ducan, et al (2012), Malik, et al. (2017) who reported that synchronous learning improves students ' academic achievement more than asynchronous learning. However, the finding contradicts the finding of LeShea (2013), Berry (2017), Malkin, et al. (2018) who reported that asynchronous learning improves students' achievement more significantly than synchronous learning. These contradictory findings may be as a result of such factors as nature of learners, learning environment/facilities, instructor and the subject matter under consideration.

The result also revealed that the male students achieved higher than the female students in online test and measurement course under synchronous learning. The result further revealed a significant difference between male and female students in favour of the males in their academic achievement in online test and measurement course under synchronous learning. The result of this study is in line with the findings of Malik, et al (2017), Kupczynski, et al (2014) who reported higher academic gains in online learning in favour of the males whereas, it disagrees with the finding of Lin and Overbaugh (2009), Amro, et al (2015), and Burtis (2017) who in their various studies reported that gender of students 'does not influence their achievement in online course. It is obvious from the result of this study that this contradiction may be due to reasons such as the category of learners studied, the subject matter, environmental conditions and teachers' factors.

The study further revealed that the male students achieved higher than the female students under asynchronous learning. The $t$-test result on the difference in the mean achievement scores of the students revealed that there exists a significant difference in the mean scores of male and female students with the male students scoring higher than the female students. This is because the $t$-value of 5.053 has an associated value of 0.000 which is less than the priori value of 0.05 . Therefore, the null hypothesis is rejected. The result of this study lay credence on the findings of Malik, et al. (2017), Kupczynski, et al. (2014) who reported that the male students achieve higher academically than the female 
students synchronous and asynchronous online learning. Contrary to this opinion, Lin and Overbaugh (2009), Amro, et al. (2015), and Burtis (2017) in their respective studies disputed that the influence of gender on students' academic achievement in online courses is not significant. At this point, one could perhaps link this disagreement to factors such as online teaching and learning facilities, attitude of learners, the subject matter as well as environmental conditions.

\section{Recommendations}

The following recommendations were put forward by the researcher in order to provide solution the problem the difference in students 'academic achievement and the influence of gender under synchronous and asynchronous learning.

1) The government and university authorities should put in place necessary ICT and related facilities that will aid online teaching and learning across all higher institutions of learning

2) Curriculum developers and educational planners should ensure that distance and related online learning should be properly integrated and made flexible in the national curriculum to ensure its efficiency in quality education delivery.

3) Teachers and instructors of distance and other related online learning should be made to undergo adequate training regarding the proper use of online facilities in teaching students in order to facilitate effective instructional delivery

4) Teacher should be encouraged to make the delivery of their instructional objectives free of gender bias

5) Students should be made to understand the need to take their education seriously whether they being supervised by their instructor or not.

\section{Conclusion}

The result of the study revealed that Synchronous learning enhances students 'academic achievement more than asynchronous learning. There is a statistically significant difference between the mean achievement score of male and female students in online test and measurement course under synchronous learning. The result further revealed a statistically significant difference between the mean achievement score of male and female students in online test and measurement course under asynchronous learning. The implications of this study to students is that students should try their best possible to ensure that distance learning (synchronous and asynchronous) is given adequate time and taking seriously by improving their information and communication technology skills. This will enable them easily navigate through their online courses and tasks. This will eliminate any difference that may arise as a result of the method of online or distance learning employed. Teachers will generally intensify their efforts toward effective delivery of instructions as well as improve their skills that will enable them cater for any weaknesses that the students may be facing. This will enable the teachers better 
understand the students and as such, instructional materials can be delivered in a way that students will easily grasp the information and become better.

\section{Acknowledgements}

The authors appreciate all our collaborators and authors whose works were consulted during the process of this study.

\section{Conflict of Interest Statement}

The authors declare no conflicts of interests.

\section{About the Author(s)}

Dr. Basil C. E. Oguguo is a seasoned psychometrician, currently lecturing in the Department of Science Education, University of Nigeria, Nsukka. He has published several books, book chapters, articles and conference papers on test and measurement, educational research, statistics, teacher education, curriculum and instruction and accounting education. orcid.org/0000-0002-0723-2248.

Christopher A. Ocheni is a postgraduate student in the department of Science education, University of Nigeria, Nsukka. He has published in many local, national and international journals of repute.

Femi Adebayo is currently a graduate student at University of Nigeria, Nsukka.

\section{References}

Amro, H. J. \& Mundy, M. A. (2015). The effect of age and gender on student achievement in face-to-face and online college algebra classes. Research in Higher Education Journal, 27, 1-22.

Berry, S. (2017). Educational outcomes of synchronous and asynchronous high school students: A quantitative causal-comparative study of online algebra 1. Unpublished doctoral dissertation. Boston, Northeastern University.

Benett, J. (2020). 9 Benefits of synchronous and asynchronous E-learning. Retrieved from https://corp.kaltura.com/blog/9-benefits-of-synchronous-and-asynchronous-elearning/

Burtis, S. (2017). Gender difference in discussion strategies of asynchronous online undergraduate psychology major students. Doctoral dissertation. Walden University

Dada, E. G., Alkali, A. H. \& Oyewola, D. O. (2019). An investigation into the effectiveness of asynchronous and synchronous e-learning mode on students' academic performance in National Open University (NOUN), Maiduguri Center. International Journal of Modern Education and Computer Science, 5, 54-64. https://doi.org/10.5815/ijmecs.2019.05.06

Digital Technology (2020). Benefits of distance education. Retrieved November 4, 2020 from https://digitalskillsglobal.com/blog/benefits-of-distance-learning-education 
Ducan, K., Kenworthy, A. \& McNamara, R. (2012). The effect of synchronous and asynchronous participation on students' performance in online accounting courses. International Journal of Accounting Education, 21(4), 431-449.

Federal Republic of Nigeria (2014). National Policy on Education (revised). Abuja. NERDC press.

Finol, M. O. (2020). Asynchronous vs synchronous learning: A quick overview. Retrieved from $\quad$ https://www.brynmawr.edu/blendedlearning/asynchronous-vssynchronous-learning-quick-overview

Great Schools Partnership. (2020). Synchronous learning. Retrieved from https://www.edglossary.org/synchronous-learning/

Griffith, J. C.; Faulconer, E. K. \& Mcmasters, B. L. (2021). The relationship between learning mode and student's performance in an undergraduate elementary statistics course in the United States. International Review of Research in Open and Distributed Learning, 22(1), 166-177. http://www.irrodl.org/plugins/generic/pdfjsviewer/pdf.js/web/viewer

Hannover Research. (2011). Distance education models and best practices. Academic Administration Practice, 1-39.

Higley, M. (2013). Benefits of synchronous and asynchronous e-learning. Available at https://elearningindustry.com/benefits-of-synchronous-and-asynchronous-elearning

Hrastinski, S. (2008). Asynchronous and synchronous e-learning. Educause Quarterly, 4, 52-55. Retrieved from https://er.educause.edu/-/media/files/articledownloads/eqm0848.pdf.

Jonsdottir, D. A. (2012). Academic achievement in 4th and 7th grade: The contribution of gender parental education, achievement goals and intelligence. Reyk, Avik: Island.

Kupczynski, L., Brown, M., Holand, G. \& Uriega, B. (2014). The relationship between gender and academic success online. Retrieved from https://files.eric.ed.gov/fulltext/EJ1020184.pdf

LeShea A. V. (2013). The effect of synchronous class session on students' academic achievement and levels of satisfaction in an online introduction to computers course. Unpublished doctoral dissertation. Liberty University

Littlefield, J. (2018). Difference between synchronous and asynchronous distance learning. Retrieved from https://www.thoughtco.com/synchronous-distancelearning-asynchronous-distance-learning-1097959

Lin, S. \& Overbaugh, R. C. (2009). Computer-mediated discussion, self-efficacy and gender. British Journal of Educational Technology, 40(6), 999-1013. https://doi.org/10.1111/j.1467-8535.2008.00889.x

Malik, M., Fatima, G., Ch, A. H \& Sarwar, A. (2017). E-Learning: Students 'perspectives about asynchronous and synchronous resources at higher education level. Bulletin of Education and Research, 39(2), 183-195. 
Malkin, A., Rehfeldt, R. A. \& Shayter, A. M. (2018). An investigation of the efficacy of asynchronous discussion on students ' performance in an online research method course. Behavior Analysis Practice, 11, 274-278.

Miles, J. (2014). The cost of convenience: How does distance education mix with the modern-day students? In Victor C. X. Wang, Victor C. X. Wang (Eds.), Handbook of research, adult and community health education: Tools, trends and methodologies. USA: IGI Global Publishers. https://doi.org/10.4018/978-1-4666-6260-5.ch017

Nworgu, B. G. (2015). Educational measurement and evaluation. Theory and Practice. Nsukka: University Trust Publishers

Ogbonna, C. G., Ibezim, N. E. \& Obi, C. A. (2019). Synchronous versus asynchronous elearning in teaching word processing: An experimental approach. South African Journal of Education, 39(2), 1-15

Okoulina, O. (2020). Syncrhonous learning simply put: Definition, benefits and tools. Retrieved from https://www.ispringsolutions.com/blog/what-is-synchronouslearning

Papadopoulou, A. (2020). What is distance learning? Definitions, examples and more. Retrieved from https://www.learnworlds.com/distance-learning/

Spinath, B. (2012). Academic achievement. Heidleberge: Elsevier Inc.

Simon, J. (2020). What is distance learning? The complete guide. Retrieved from https://www.techsmith.com/blog/distance-learning/

Simonson, M., Smaldino, S., Albright, M., \& Zvacek, S. (2012) Teaching and learning at a distance: Foundations of distance education. (5th ed.). Boston: Pearson.

Strenze, T. (2007). Intelligence and socioeconomic success: A meta- analytic review of longitudinal research. Intelligence, 35, 581-592.

Techsmith (2021). What is distance learning? The complete guide (2021). Retrieved from https://www.techsmith.com/blog/distance-learning/

The University of Adelaide (2014). Measurement, assessment and evaluation. Retrieved from https://www.adelaide.edu.au/course-outlines/104713/2/quad-4/2014/

Tichauer, R. (2015). The importance of distance learning. Retrieved from https://educonnect.co.za/the-importance-of-distance-learning/

Viewsonic (2020). The pros and cons of asynchronous distance learning. Retrieved from https://www.viewsonic.com/library/education/the-pros-and-cons-ofasynchronous-distance-learning/ 
Creative Commons licensing terms

Authors will retain the copyright of their published articles agreeing that a Creative Commons Attribution 4.0 International License (CC BY 4.0) terms will be applied to their work. Under the terms of this license, no permission is required from the author(s) or publisher for members of the community to copy, distribute, transmit or adapt the article content, providing a proper, prominent and unambiguous attribution to the authors in a manner that makes clear that the materials are being reused under permission of a Creative Commons License. Views, opinions and conclusions expressed in this research article are views, opinions and conclusions of the author(s). Open Access Publishing Group and European Journal of Open Education and E-learning Studies shall not be responsible or answerable for any loss, damage or liability caused in relation to/arising out of conflict of interests, copyright violations and inappropriate or inaccurate use of any kind content related or integrated on the research work. All the published works are meeting the Open Access Publishing requirements and can be freely accessed, shared, modified, distributed and used in educational, commercial and non-commercial purposes under a Creative Commons Attribution 4.0 International License (CC BY 4.0). 